\title{
The stratospheric polar vortex and sudden stratospheric warmings
}

Article

Accepted Version

Lee, S. H. (2021) The stratospheric polar vortex and sudden stratospheric warmings. Weather, 76 (1). pp. 12-13. ISSN 0043-1656 doi: https://doi.org/10.1002/wea.3868 Available at https://centaur.reading.ac.uk/93156/

It is advisable to refer to the publisher's version if you intend to cite from the work. See Guidance on citing.

To link to this article DOI: http://dx.doi.org/10.1002/wea.3868

Publisher: Wiley

All outputs in CentAUR are protected by Intellectual Property Rights law, including copyright law. Copyright and IPR is retained by the creators or other copyright holders. Terms and conditions for use of this material are defined in the End User Agreement.

\section{www.reading.ac.uk/centaur}

\section{CentAUR}

Central Archive at the University of Reading

Reading's research outputs online 


\title{
The Stratospheric Polar Vortex and Sudden Stratospheric Warmings
}

\author{
Simon H. Lee \\ Department of Meteorology, University of Reading
}

\section{What is the stratospheric polar vortex?}

During winter, the poles become much colder than the tropics, resulting in a strong meridional temperature gradient, which is strongest in the stratosphere. On these large scales, the vertical wind shear (the change in wind speed with height) is in a balanced state with the temperature gradient. Thus, the cold stratospheric air over the winter pole is encircled by a belt of strong westerly winds - known as the polar night jet stream. The polar night jet and the cold air which it encircles collectively form the cyclonic stratospheric polar vortex.

The strength of the polar vortex is often diagnosed using the zonal-mean zonal winds (i.e., the average wind speed around a latitude band) at $10 \mathrm{hPa}$ (around $30 \mathrm{~km}$ ) and $60^{\circ} \mathrm{N}$. By this measure, the Arctic vortex on average forms in the last week of August, reaches peak strength in January, and dissipates in April. In the summer months, the stratosphere is filled with easterly winds.

\section{How does the polar vortex influence weather?}

The polar vortex can affect the position and strength of the tropospheric jet streams. When the stratospheric vortex is strong, the jet streams in the troposphere tend to be stronger and shifted toward the pole. In this configuration, cold air tends to be locked up over the Arctic. Areas like the British Isles are often stormy and wet, as the strong jet stream aids the development of deep areas of low pressure. Conversely, when the polar vortex is weak, the jet stream in the troposphere tends to be weaker, shifted further south, and wavier, allowing cold air to plunge out of the Arctic into the mid-latitudes. These two different patterns are known respectively as the positive and negative phases of the Arctic Oscillation (and the closely related North Atlantic Oscillation), which describe the strength and latitude of the tropospheric jet streams.

However, the stratospheric polar vortex is only one of several factors that can affect tropospheric weather patterns during winter. While its influence can be significant, it is not always strong or the same across different events. Determining when and why the troposphere responds more strongly to some stratospheric changes is an area of current research.

\section{What influences the strength of the polar vortex?}

Waves in the mid-latitude jet stream flow, known as Rossby waves, can propagate vertically from the troposphere into the stratosphere when the winds are westerly. Only the longest waves can do so (usually, those with zonal wavenumbers 1-3). In the stratosphere, these waves can break, akin to waves breaking on a beach, decelerating the polar night jet. Various tropospheric phenomena can alter the amount of wave activity emanating from the troposphere - such as blocking and tropical convection - but the stratosphere itself can also control how much it can receive. For example, if the vortex is too strong, then waves cannot propagate into it.

In the Northern Hemisphere, the layout of the continents and mountain ranges means there is much more of this wave activity than in the Southern Hemisphere. Consequently, the Arctic stratospheric vortex is much weaker and more variable than its Antarctic counterpart. It is for 
this reason that, unlike the Antarctic, a large ozone hole does not form in the Arctic stratosphere each winter. The much colder temperatures within the Antarctic vortex allow for the formation of polar stratospheric clouds that catalyse ozone depletion.

\section{What is a sudden stratospheric warming?}

A particularly extreme case of stratospheric vortex weakening is known as a sudden stratospheric warming (SSW), so-called because of the rapid rise in the temperature of the polar stratosphere $\left(\sim 50^{\circ} \mathrm{C}\right.$ in a few days). Associated with the rapid rise in temperature is a dramatic deceleration of the polar night jet. In cases when this is particularly strong, the event may be classified as a major SSW (usually defined as easterly zonal-mean winds at $10 \mathrm{hPa}$ and $60^{\circ} \mathrm{N}$ ). Major SSWs occur approximately once every other winter in the Arctic, while only 1 has been observed in the Antarctic in 2002; a significant deceleration in 2019 came close.

SSWs take on a variety of forms. The two most common categories are those where the polar vortex is nudged off the pole in a displacement event, driven largely by amplification of wavenumber 1, and those where it is broken into two smaller vortices in a split event, driven largely by an amplification of wavenumber 2. An example of a split-type SSW in January 2009 is shown in Figure 1, contrasted with an undisturbed vortex during February 2020. The disrupted vortex following an SSW can persist for several weeks until it reforms.

\section{How predictable is the stratosphere?}

Generally, the stratosphere varies on longer timescales than the troposphere, so is more predictable overall. However, the onset of both major SSWs and strong vortex events can be difficult to predict more than 2 weeks in advance (although probabilistic skill exists for seasonal forecasts), partly due to the predictability of the wave activity from the troposphere and how it interacts with the vortex. Despite this limitation, forecasts which are started in particularly weak or strong vortex states tend to have better longer-term skill. This, combined with the long duration of extreme stratospheric states, can provide longer-term ('sub-seasonal') predictability beyond the typical 2-week timeframe of weather forecasts.

\section{Further Reading}

Charlton, A.J. and Polvani, L.M., 2007. A new look at stratospheric sudden warmings. Part I: Climatology and modeling benchmarks. Journal of Climate, 20(3), pp.449-469, https://doi.org/10.1175/JCLI3996.1

Lee, S.H. and Butler, A.H., 2020. The 2018-2019 Arctic stratospheric polar vortex. Weather, 75(2), pp.52-57, https://doi.org/10.1002/wea.3643

Kidston, J., Scaife, A.A., Hardiman, S.C., Mitchell, D.M., Butchart, N., Baldwin, M.P. and Gray, L.J., 2015. Stratospheric influence on tropospheric jet streams, storm tracks and surface weather. Nature Geoscience, 8(6), pp.433-440, https://doi.org/10.1038/ngeo2424 
17 February 2020
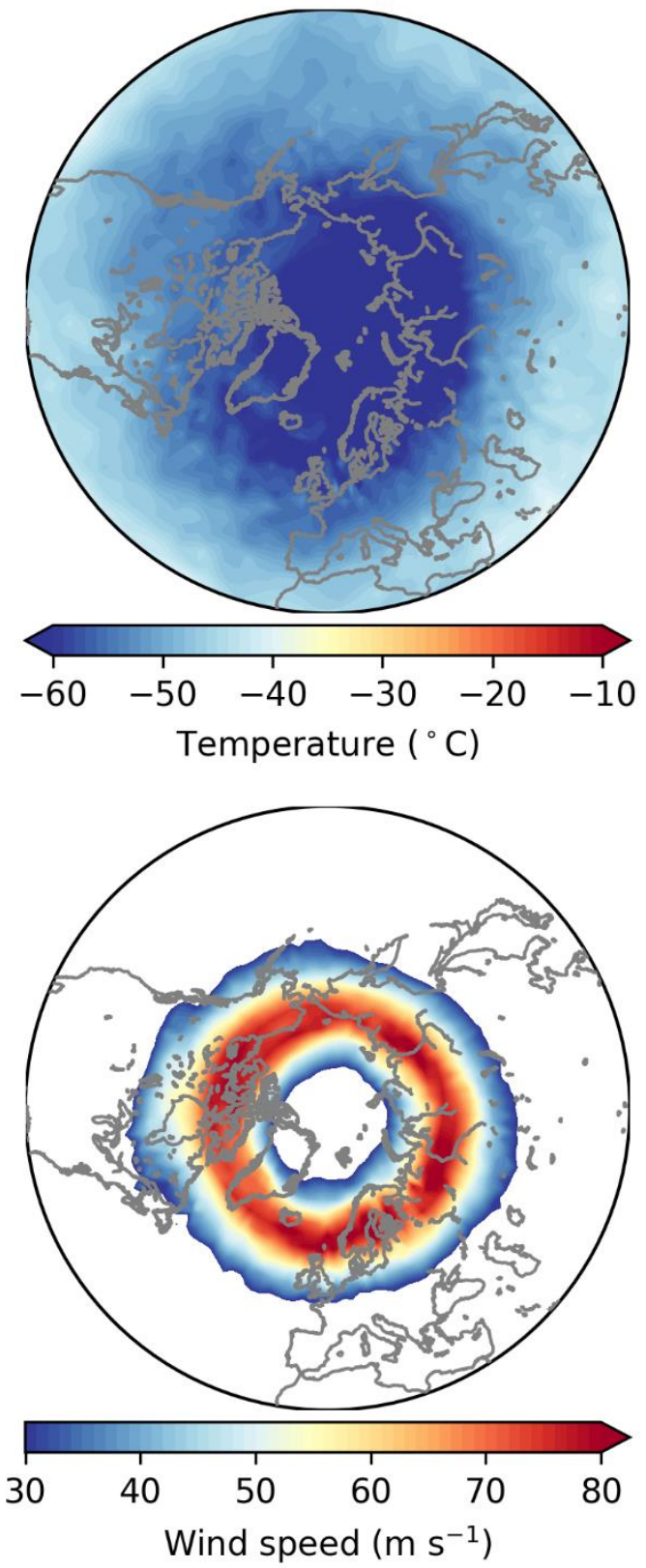

25 January 2009
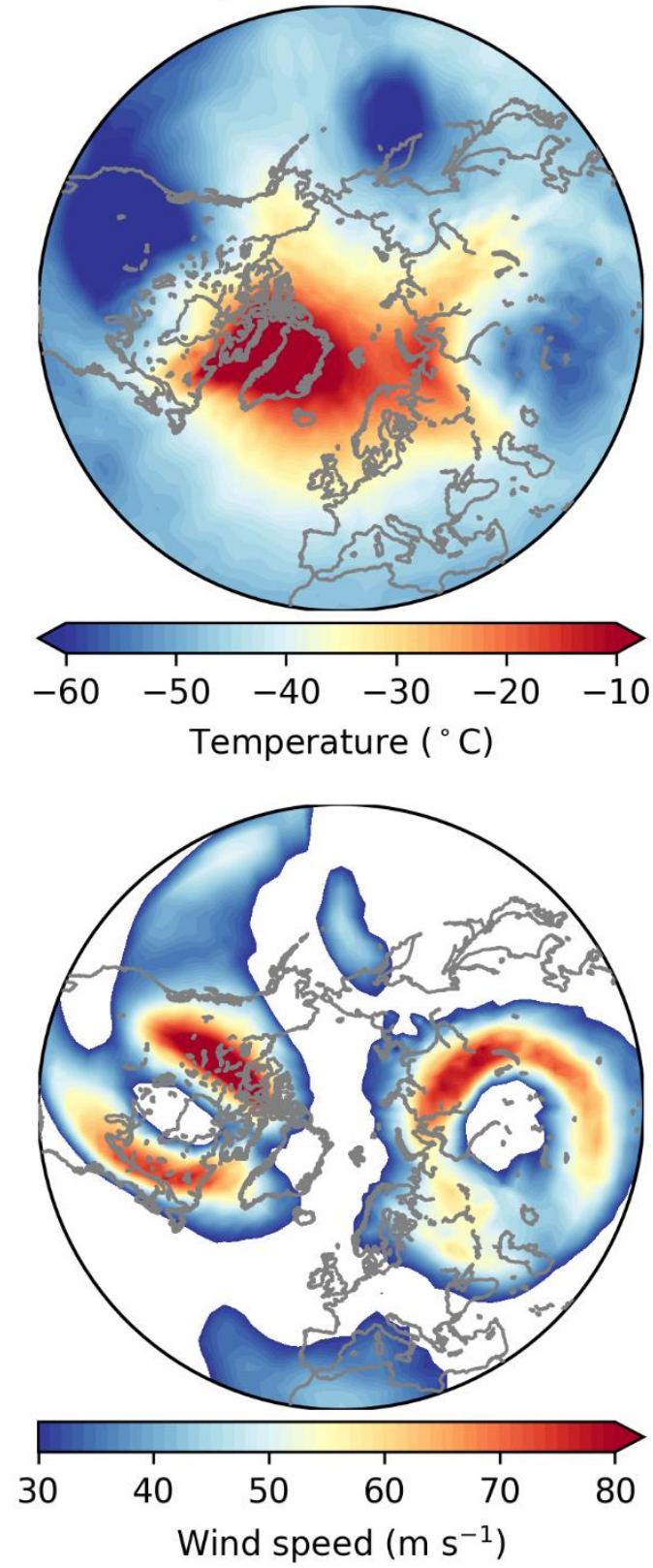

Figure 1: $10 \mathrm{hPa}$ temperatures (top row) and wind speeds (bottom row) during a strong vortex event on 17 February 2020 (left-hand column) and during a major SSW on 25 January 2009 (right-hand column). Data from ECMWF ERA5 reanalysis. 